\title{
TENSÕES ÉTNICO-CULTURAIS NA LITERATURA DE CABO VERDE: ESPACIALIDADES FEMININAS EM “LIBERDADE ADIADA”, DE DINA SALÚSTIO
}

\author{
Paulo Freitas Gomes ${ }^{1}$ \\ Vanessa Riambau Pinheiro ${ }^{2}$
}

\begin{abstract}
RESUMO: Nossa pesquisa parte de uma sucinta exposição da literatura cabo-verdiana para chegar à literatura contemporânea, a partir da análise de um conto de Dina Salústio. Aspectos como a independência foram fundamentais para a reconfiguração do imaginário insular, que ampliou suas temáticas: desde os limites territoriais e o domínio português de outrora até os espaços de natureza mais íntima de seus sujeitos. Por meio de uma abordagem bibliográfica e de teor crítico, nosso objetivo, a partir da explanação inicial feita, é compreender as tensões peculiares ao cenário étnico e cultural de Cabo Verde da atualidade, dando abertura para o diálogo sobre a representação do feminino no conto "Liberdade adiada”, da obra Mornas eram as noites (2019). Corroboramos às investigações de APPIAH (2007), FANON (1983), GOMES (1993, 2000, 2008), LARANJEIRA (1995), LOBO (2016), entre outros aportes teóricos para aprofundar nossas argumentações.
\end{abstract}

PALAVRAS-CHAVE: Literatura cabo-verdiana; Tensões étnico-culturais; Dina Salústio; Espacialidades femininas.

ABSTRACT: Our research starts from a succinct exhibition of Cape Verdean literature to arrive at contemporary literature, from the analysis of a short story by Dina Salústio. Aspects such as independence were fundamental for the reconfiguration of the island imaginary, which broadened its themes: from the territorial limits and the Portuguese domain of yesteryear to the most intimate spaces of its subjects. Through a bibliographic and critical approach, our objective, from the initial explanation made, is to understand the tensions peculiar to Cape Verde's ethnic and cultural scene of today, opening for dialogue on the representation of the female in the short story "Delayed Freedom", of the work Warm were the nights (2019). We corroborate the investigations of APPIAH (2007), FANON (1983), GOMES (1993, 2000, 2008), LARANJEIRA (1995), LOBO (2016), among other theoretical contributions to deepen our arguments.

KEYWORDS: Cape Verdean literature; Ethnic-cultural tensions; Dina Salústio; Female spatialities.

\footnotetext{
1 Doutorando no Programa de Pós-Graduação em Letras da Universidade Federal da Paraíba. E-mail: pdefreitasgomes6@gmail.com

2 Professora Adjunta de Literaturas de Língua Portuguesa na Universidade Federal da Paraíba. Possui pós-doutorado em Estudos Africanos, concluído em 2017 na Universidade de Lisboa e publicou diversos livros na área de crítica literária. E-mail: vanessariambau@gmail.com
} 


\section{NÓS E ELES: TENSÕES NO CENÁRIO LITERÁRIO DE CABO VERDE}

A trajetória literária cabo-verdiana está absorta na transição histórica e nas metamorfoses políticas deste país insular. Similar aos outros territórios que estiveram sob o domínio da metrópole portuguesa, suscetíveis às influências do colonizador, Cabo Verde apresenta, em seus primeiros registros literários, referências de cordialidade e ovação da cultura lusitana.

Compreendemos o colonialismo como um projeto de soberania política e social eurocêntrica, como uma maneira de sobreposição e naturalidade da bifurcação dominante/ dominado. A primeira parte constituinte deste estratagema localiza-se sobre a representação de um grupo líder, detentor de artifícios aliciantes e reconhecido como aquele que introduz no território invadido um sentimento de inferioridade, facilitando sua consagração enquanto explorador (SIQUEIRA, 2014, p. 67).

É característica dos primeiros registros poéticos de Cabo Verde um tom de respeitabilidade e agradecimento pela presença de Portugal e de seus valores culturais amalgamados neste Estado-nação (GOMES, 1993, p. 23). O país em tempos remotos tornou-se depósito de africanos escravizados, trazidos de distintas partes da África, com o intuito de serem enviados a outros continentes, principalmente à América. Por conseguinte, fora designado como ponto de apoio para o desdobramento do tráfico negreiro, devido a sua localização privilegiada entre os continentes africano, europeu e americano (MADEIRA, 2014, p. 02).

Conforme a abordagem generalizada de Brito Semedo (2001, p. 254-256) sobre o panorama das literaturas cabo-verdianas temos uma produção literária dividida em três momentos, com base na afirmação, combate e realização simbólica: a fase do sentimento nativista (1856-1932), também denominada como Crioulidade; a fase de consciência regionalista (1932-1958) ou geração dos claridosos e, por último, a fase de afirmação nacionalista (19581975).

Com base nas referências de Brito Semedo, também discutidas por João P. Madeira (2014, p. 151), a geração dos Nativistas eclode do anseio de igualdade identitária, ou seja, os intelectuais que formavam uma pequena parcela de expressão crítica local manifestaram o interesse dos cabo-verdianos serem percebidos com os mesmos direitos dos viventes da metrópole. Compreende-se que simultâneo ao desejo de autonomia do arquipélago, sem eximir-se das influências culturais do continente africano e de seu pertencimento geográfico, não existia a hipótese de desprendimento das origens lusitanas.

A crioulidade é o principal fator para o projeto nativista, no qual se articula a fusão de civilizações. Por esta razão, os autores e os escritos literários desse período são vinculados à expressão dos "Portugueses de Lei e Cabo-verdianos de alma" (MONTEIRO, 1999, p. 175). Circulava a ideia sobre Cabo Verde ser uma região europeia em chão africano. A crítica social, os questionamentos sobre o sistema escravocrata e a relação de poder eram temas apresentados nos textos, entretanto, sem abrir mão dos vestígios que implicam o predomínio de uma cultura genuína. No que concerne à discussão retratada, João Nobre de Oliveira ressalta que: 
Os Nativistas defendiam na prosa o homem cabo-verdiano e os seus valores chegando em dados momentos a assumirem posições antiportuguesas, mas nos temas dos seus contos e dos seus poemas e no seu próprio estilo de escrever não há nada que os separe dos seus congéneres portugueses e enaltecem Portugal e seus heróis mais do que os portugueses (OLIVEIRA, 1998, p. 480).

A noção de identidade ambígua, decorrente do não reconhecimento do "nós" (nativos das Ilhas) e "eles" (mantenedores das acepções europeias, os metropolitanos), gerou desconforto relacionado à falta de maturidade e consciência crítica dos literatos, por não reconhecer no projeto colonial a disparidade entre colonizador e colonizado, dando margem à contradição. Eugénio Tavares, José Lopes, Pedro Cardoso, Luís Loff de Vasconcelos são alguns dos representantes desse primeiro momento.

Em 1936 com a criação da revista Claridade, na cidade de Mindelo, Ilha de São Vicente, emergem outras cenas da literatura insular. Baltasar Lopes, Jorge Barbosa e Manuel Lopes formam o periódico com o propósito da circulação de textos que pautassem discursos denunciativos sobre o desamparo sofrido pelos colonos, por parte das ordens governamentais portuguesas. Decerto, a supremacia da pátria já estava posta em dúvida.

"Fincar os pés na terra" tornou-se lema para a nova ordem artística da época. A saber, temos a recorrência dos agravantes regionais, sobretudo a localização geográfica e a dificuldade de acesso ao território. A seca e o exílio, assim como a fome e a morte eram conteúdos cristalizados nas composições poéticas (FERNANDES, 2006, p.76).

Segundo Russel Hamilton (1984, p. 122) as publicações inerentes ao período claridoso são influenciadas por razões externas. Isso se dá pelo contato de seus integrantes com a Revista Presença (1927-1940), considerada como dispositivo ideológico e político português para fomentação de depoimentos adversos aos padrões elitistas e ao academicismo exacerbado. Simpatizante dos ideais futuristas articulados às novas tendências literárias visionadas na Europa, no início do século XX.

Embora o grupo dos claridosos tenha sido responsável por um trabalho intenso de resgate sociocultural e geográfico, dando abertura para mostrar ao mundo a verdadeira face e a distinção cotidiana do homem da terra, não estivera alheio às recriminações baseadas em discursos que o discriminavam enquanto um movimento assimilacionista. Tal visão decorre da maneira como Cabo Verde, até então, era exposto pelos escritores, sempre comparado, semelhantemente, com o Algarve ou a outras regiões portuguesas. Outrossim, também se aponta uma estratégia de incorporação por consequência do diálogo com o regionalismo brasileiro.

Refutando o modelo de consciência regionalista adotado anteriormente, procura-se refletir sobre o continente africano e sua contribuição identitária para a formação e o modo de vida da população insular (MADEIRA, 2014, p. 159). A visão regional é dissipada, contudo, a proposta de releitura do imaginário colonial e a disposição em estabelecer a África em primeiro plano são presságios da Independência. Desta maneira, João Vasconcelos conclui:

A geração dos nacionalistas viria a esboçar, numa rede intensa de intelectuais, novas formas de pensar e novas preocupações com a identidade nacional, que antes 
se apelidava de consciência regionalista, que Cabo Verde é uma região de Portugal como o Minho, Algarve, Madeira, Açores e etc.. e que partilhava do mesmo universalismo português e das mesmas similitudes. A geração dos nacionalistas é "filha da conjuntura internacional do pós-guerra, esta geração encetou luta aberta contra o colonialismo português, sob as bandeiras da independência nacional e do socialismo" (VASCONCELOS, 2004, p. 177).

Diferentemente dos outros territórios colonizados, Cabo Verde não provou de confrontos armados para alcançar a sua libertação. Após algumas negociações, em 05 de julho de 1975, na cidade de Praia, capital de Cabo Verde, o país foi declarado um território independente. Nesta fase de reafirmação das origens africanas e conscientização literária, podemos citar alguns autores representativos como Onésimo Silveira, Felisberto Vieira Lopes, Aguinaldo Fonseca, Ovídio Martins, Gabriel Mariano, além do próprio Amílcar Cabral, entre outros.

Episódios concernentes ao fato aludido que foram discutidos em momento anterior deste trabalho, foram descritos em romances, contos e poemas orientados pelo arquétipo regionalista. A título de exemplo, citamos os romances Os Flagelados do Vento Leste (1959), de Manuel Lopes; Chiquinho (1947), de Baltasar Lopes, etc. Retomando o texto de Ovídio Martins, apesar da recordação feita ao poema "Vou-me embora pra Pasárgada", presente na obra Libertinagem (1930), cuja autoria é de Manuel Bandeira, encontramos uma inversão discursiva. Enquanto Bandeira, utopicamente, descreve Pasárgada como refúgio absoluto, Ovídio Martins o renega.

Até o momento traçamos um breve estudo acerca da literatura de Cabo Verde, trazendo para o bojo da discussão elementos étnico-culturais propostos nas primeiras expressões poéticas até o ano de 1975, data singular para o histórico das Ilhas. Do mesmo modo, dialogamos com epistemologias firmadas nos estudos africanos e pós-coloniais.

A literatura cabo-verdiana, inerente ao período nacionalista, desempenhou um papel importante para o fomento das produções atuais. Isto posto, reconhecemos que os intelectuais da época preconizaram uma abordagem de escrita a partir de seus questionamentos e retratavam suas percepções a respeito dos paradigmas da colonização e dos limites provocados pela desigualdade social entre os ilhéus.

As expressões literárias peculiares à "reafricanização dos espíritos" subsidiaram performances posteriores que desassistem um ideário marcado pela cabo-verdianidade e instituem-se por estratégias universalizantes para a compreensão das individualidades, onde os questionamentos prevalecem sobre as afirmativas preestabelecidas.

Nossa problematização a seguir estará voltada à produção literária de Dina Salústio, escritora que dialoga com a contemporaneidade e apresenta em seus escritos assuntos importantes para os tempos atuais, os quais exigem repercussão e não podem estar fadados ao esquecimento.

Para a pesquisadora Simone Caputo (2000, p. 115), vozes como a de Dina Salústio são importantes na literatura. Além de romper com um projeto liderado pela presença masculina, desdobra-se com interesse em relatar as experiências das mulheres, divulgando um 
mundo camuflado pela hegemonia patriarcal. Embora o termo independência tenha sido visitado pelas literaturas insulares, não foi explorado em sua totalidade, retirando de alguns sujeitos sociais o seu protagonismo.

\section{NO ESPELHO DA LITERATURA, O REFLEXO DA VIDA}

Na ocasião em que Dina Salústio afirma sua preocupação em decifrar dilemas cotidianos, recordamos de outras vozes africanas como Noémia de Souza, quando tenta diminuir sua importância em se fazer/sentir escritora, a propósito do seu papel pioneiro envolto da obra Sangue Negro (2001): "Escrever foi uma brincadeira, tanto que eu deixei de escrever e pronto, acabou. Eu acho que, quando comecei a escrever, isso foi uma opção, no fundo, de dar voz àqueles que não têm voz, um bocado isso" (CHABAL, 1994, p. 114). Seguindo esta convicção Paulina Chiziane insiste no seu papel de "contadora de histórias e não de romancista, é desta maneira como gosta que a tratem".

Sabemos que assumir tal posição pode ser uma estratégia condicionada à esfera editorial, cujo intuito é chamar atenção da crítica e intensificar a publicização da obra, ou até mesmo para manter um diálogo mais próximo com o leitor. Todavia, acreditamos que para as realidades mencionadas, coexiste a prioridade em relatar vivências femininas, doutrinas segregacionistas e desmistificar discursos únicos, por se tratar de questões ainda pouco debatidas.

Elaborar um arcabouço crítico através de performances articuladas ao universo literário tem se tornado uma maneira profícua para divulgar reflexões sobre a existência política dos sujeitos sociais e seus determinantes. Esta observação pode ser ratificada, principalmente, com a publicação de obras a partir do século XX, sendo discutida por Antonio Candido em Literatura e Sociedade: Estudos de Teoria e História Literária (1965), quando o autor efetua um estudo sobre a arte e o meio social, com distinção para os elementos texto e contexto, categorias integrantes da crítica dialética.

Portanto, ousamos mencionar que as obras estão sendo formadas para atender uma camada social que não se percebia em repertórios secularmente orientados por critérios patrilineares (ZOLIN, 2009, p. 08), ou seja, que obedeciam ao sistema patriarcal estruturante das sociedades de modo geral.

O atual cenário não se trata apenas de uma evolução nas Letras, mas se desenvolve no campo da Filosofia, Antropologia, História, das Ciências Sociais, etc. As reflexões partem dos estudos da cultura, identidades, negritudes, gêneros e sexualidades. De modo particular, interessa-nos observar como a representação do feminino está inserida na obra de Dina Salústio, pois, conforme Gomes (2008, p. 93) embora a população das Ilhas seja constituída, em sua maioria, por um público feminino, nem por isso a região está livre da mentalidade patriarcal. O conto que será objeto de nosso estudo, "Liberdade adiada", evidencia este traço social: no texto, temos o relato do narrador que conta a história de uma personagem - não nomeada - com quem teria tido uma conversa casual na praia. A personagem é jovem, pobre, tem vários filhos e sente-se infeliz e sem perspectivas. Todo dia sonha em cometer suicídio para obter a sonhada liberdade. Não nomear a personagem é uma maneira de a autora 
universalizar o discurso, cuja proposta é fazer com que muitas mulheres sejam alcançadas e seus desconfortos estejam representados por meio dos lamentos da figura retratada no enredo. Também é uma maneira de expressar a invisibilidade social desta personagem.

Sentia-se cansada. A barriga, as pernas, a cabeça, o corpo todo era o enorme peso que lhe caía irremediavelmente em cima. Esperava que a qualquer momento o coração lhe perfurasse o peito, lhe rasgasse a blusa. Como seria o coração? Teria mesmo aquela forma bonita dos postais coloridos? Seriam todos os corações do mesmo formato? ... Será que as dores deformam os corações? Pensou em atirar a lata de água ao chão, esparramar-se no líquido, encharcar-se, fazer-se lama, confundir-se com aqueles caminhos que durante anos e mais anos lhe comiam a sola dos pés, lhe queimavam as veias, lhe roubavam as forças. Imaginou os filhos que aguardavam e que já deviam estar acordados. Os filhos que ela odiava! Aos vinte e três anos, disseram-lhe que tinha o útero descaído. Bom seria que caísse de vez! Estava farta daquele bocado de si que, ano após ano, enchia, inchava, desenchia e lhe atirava para os braços e para os cuidados mais um pedacinho. Não. Não voltaria para casa (SALÚSTIO, 2019, p. 09).

"Liberdade adiada" é uma narrativa breve, porém intensa. Em poucas linhas consegue transitar por vários temas que tocam a vida da mulher cabo-verdiana. A brevidade é um traço distintivo das narrativas integrantes da obra Mornas eram as noites (1994), entretanto, não se estreita à extensão do texto, mas soa como crítica ao espaço abreviado e imposto à figura feminina.

Embora as lideranças governamentais estejam abertas às necessidades deste público, elaborando ações que visam à segurança e tentam rever os reflexos da dominação masculina, muita coisa ainda precisa ser feita para proporcionar igualdade entre gêneros em Cabo Verde. As desvantagens das mulheres são colocadas por Gomes (2008, p. 93) como consequência de uma sociedade instável, todavia, com o governo assumindo responsabilidades e investindo na promoção feminina, "tem efeitos multiplicadores da família à nação".

Estamos a dialogar sobre um texto que tem como protagonista uma jovem mãe que tem sob sua responsabilidade a condução do espaço doméstico e a sobrevivência de seus dependentes. Sem antropônimo, percebe-se cansada da uniformidade dos seus dias e do marasmo de seu destino. Logo, sua existência limita-se ao lar e ao ofício da maternidade. É relevante notar que essa representação feminina foge completamente à idealização da mãe perfeita, apesar do amor aos filhos ser o único fato que impede a protagonista de cometer suicídio, como podemos aferir na passagem a seguir: "À borda do barranco, com a lata de água à cabeça e a saia batida pelo vento, pensou nos filhos e levou o coração ao peito" (SALÚSTIO, 2019, p. 10). O amor aos filhos, entretanto, não é capaz de realizar plenamente esta mulher, o que a difere do modelo tradicional de maternidade. Essa supervalorização da maternidade é muito própria da cultura africana; apesar de o continente possuir uma vasta extensão territorial e multiplicidade étnica, a figura da mãe tem uma importante dimensão espiritual que lhe confere um valor universal (CHRISTIAN, 1994, p. 96). Apesar do estudioso referido na citação anterior ter realizado um estudo específico sobre a obra da nigeriana Buchi Eme- 
cheta, podemos ampliar sua análise para o continente africano de modo geral, respeitadas as especificidades étnicas de cada região. Destarte, para os africanos, de modo geral, uma existência espiritual sem descendência é considerada nula, tendo em vista a crença de que os mortos (co)existem em outra dimensão, devendo ser lembrados. O papel da mãe, além de gerar a descendência, é também o de constituir um elo com a ancestralidade, criando uma ponte entre o passado e o futuro.

O narrador localiza-se em terceira pessoa, conhecedor dos fatos, expõe com intimidade a vida simples da jovem mãe. Observa com empatia o espaço de miserabilidade em que as ações procedem, portanto, temos uma voz enunciativa que coordena, atentamente, o relato das circunstâncias. Deste modo, podemos imaginar este narrador como testemunha dos eventos da trama, sua participação será confirmada em parte posterior da narrativa. $\mathrm{O}$ enredo se desenvolve como imagens que decodificam um cenário de desigualdade social e desgaste feminino.

A autora sintetiza a história de mulheres que vivenciam a monoparentalidade, tendo como plano de fundo a solidão, sentimento que se torna um conflito não pela ausência de pessoas, mas por causa da desqualificação dos sujeitos. A desumanização flui da condição do ser mulher em uma dada comunidade. Temos uma personagem que durante os seus afazeres e caminhos rotineiros, tão bem conhecidos, carrega consigo suas inquietudes, chegando a comparar-se à própria lama produzida, caso deixasse entornar a água que levava para casa. Isso porque, no seu entender, não passava daquilo, tornou-se a personificação do chão que todos pisam. Suas dores a faziam pensar em seus filhos, sendo eles também responsáveis, mesmo que indiretamente, por sua degradação. Em Cabo Verde algumas mulheres assumem, integralmente, “a responsabilidade de cuidar das suas famílias, adicionadas às tarefas domésticas estão as atividades externas (profissionais), além de assistir outros parentes" (LOBO, 2016, p. 16).

A composição familiar no mundo atual, mesmo nas sociedades menos desenvolvidas e marcadas por traços conservadores, não se restringe a uma formação unilinear. Como instituição múltipla, resultam das pluralidades culturais, políticas e econômicas do meio social (LOBO, 2016, p. 16). O conto em destaque referencia a matricentralidade, já que a figura masculina em momento algum é mencionada. Por conseguinte, inferimos que este absenteísmo parte de motivos alternantes como a emigração, abandono conjugal, poligamia, viuvez ou até mesmo quando as mulheres se sentem desamparadas por seus companheiros que não as auxiliam quando há necessidade, motivo bem recorrente.

Ademais, é válido reiterar que por não se encontrar numa família padrão, as mulheres cabo-verdianas com este perfil estão assujeitadas às normas centradas na masculinidade. $\mathrm{O}$ fato de a protagonista possuir um útero, em detrimento de sua realidade, não é benesse, é parte de seu corpo que a martirizava (SALÚSTIO, 2019, p. 09):

O barranco olhava-a, boca aberta, num sorriso irresistível convidando-a para o encontro final. Conhecia aquele tipo de sorriso e não tinha boas recordações dos tempos que vinham depois. Mas um dia havia de o eternizar. E se fosse agora, no instante que madrugava? (...) Atirar-se-ia pelo barranco abaixo. Não perdia nada. Aliás nunca perdeu nada. Nunca teve nada para perder. Disseram-lhe que 
tinha perdido a virgindade, mas nunca chegou a saber o que aquilo era. À borda do barranco, com a lata de água à cabaça e a saia batida pelo vento, pensou nos filhos e levou as mãos ao peito. O que tinha a ver os filhos com o coração? Os filhos... Como ela os amava, Nossenhor! Apressou-se a ir ao encontro deles. O mais novito devia estar a chamar por ela. Correu, deixando o barranco e o sonho de liberdade para trás. (SALÚSTIO, 2019, p. 10, grifos nossos).

O suicídio é apontado como o caminho para o alcance da liberdade desta personagem infeliz e sem perspectivas na vida. Sabemos que o cansaço e os desafios diários são realidades que, com o passar do tempo, e apoiadas por alusões misóginas, como a mencionada na citação a respeito do valor de sua virgindade que fora perdida naturalizaram-se no universo feminino. Também podemos inferir que a protagonista é alvo de exclusão social e de preconceito, a partir do que é mencionado no excerto anterior: "Disseram-lhe que tinha perdido a virgindade, mas nunca chegou a saber o que aquilo era." (SALÚSTIO, 2019, p. 10).

Apesar de não haver nenhum personagem masculino no conto, a dominação patriarcal atua neste texto através da invisibilidade desta mulher, abandonada à própria sorte pelo pai de seus filhos sem contar com a ajuda de ninguém. A única pessoa que ouve seus lamentos provavelmente é uma forasteira que desconhece seus problemas e não a julga premeditadamente.

Em meio às agruras, atirar-se barranco abaixo seria sua possível liberdade, conquistada com a morte, que lhe possibilitaria escapar das funções sociais de gênero que a sociedade demanda. Pôr fim a sua existência seria o único ganho em um somatório de perdas. Ao ser tomada pelo sentido da maternidade e pela necessidade de assumir o papel social que lhe é imputado socialmente, a protagonista resolve adiar a liberdade desejada.

\section{CONSIDERAÇÕES FINAIS}

Os estudos pós-coloniais no âmbito da literatura estão atravessados por questões políticas e discursos contrapostos às ofertas de adequação cultural. É inevitável pensar no aparecimento de vozes oprimidas por padrões conservadores oriundos do sistema patriarcal.

Mesmo com a atual configuração do mundo contemporâneo, não é difícil encontrarmos as situações de dominação decorrentes de estruturas seletivas, norteadas por imposições socioculturais, nas quais o sujeito marginalizado não encontra maneiras de individuação e autonomia.

É a partir desta condicionante que Gayatri Spivak escreve o texto Pode o Subalterno falar?, tendo sua primeira publicação no ano de 1985, em forma de artigo. A autora parte da premissa de que não há inexistência de voz, mas de espaço para que os sujeitos subalternizados possam ser visibilizados. Por conseguinte, cruzando as reflexões de Spivak com a proposta desta pesquisa, em particular sobre o fazer literário de Dina Salústio, percebemos a necessidade de propagação de textos de denúncia como o exposto, classificados pela autora caboverdiana como histórias da vida. Pontuamos a exposição de subjetividades submetidas a acordos convencionais, sobretudo, no que tange à existência das mulheres, pois, na maio- 
ria das vezes, são expostas às aspirações centradas na superioridade masculina.

Podemos concluir, de acordo com a discussão apresentada, que ainda que a literatura cabo-verdiana tenha começado como exercício de configuração de uma nação recém-formada, através de vozes que expressassem o mesmo caráter coletivo, por meio de uma abordagem genérica das Ilhas. Mesmo em sua fase mais ponderada, em que o âmago da discussão se constata, principalmente, por uma leitura do cotidiano da sociedade insular e no reconhecimento de sua gênese africana, não é comum encontrarmos produções que explorem as corporalidades e outros aspectos mais íntimos presentes na vida de seus sujeitos sociais. Em contrapartida, Dina Salústio, em uma perspectiva contemporânea, perscruta as dinâmicas de seu país, e por meio da sua obra partilha as múltiplas facetas que subsistem nas experiências femininas, além de expressar conflitos existentes na sociedade, como maternidade precoce, pobreza, infelicidade e invisibilidade social. 


\section{REFERÊNCIAS}

APPIAH, Kwane Anthony. Na Casa de Meu Pai: a África na invenção da cultura. Trad. Vera Ribeiro. Rio de Janeiro: Contraponto, 2007.

BANDEIRA, Manuel. Libertinagem. Rio de Janeiro: Paulo Pongetti \& Cia, 1930.

CABRAL, Amílcar. Unidade e Luta: A arma da teoria. Lisboa, Seara Nova, 1978.

CADAMOSTO, Luis de. Navegação primeira de Cadamosto e Usodimare e Navegação segunda de Cadamosto e Usodimare. In: Vitorino Magalhães Godinho (org.). Documentos sobre a expansão portuguesa. Lisboa: Cosmos, 1956.

CANDIDO, Antonio. Literatura e Sociedade: Estudos de Teoria e História Literária. São Paulo: Companhia Editora Nacional, 1965.

CHABAL, Patrick. Vozes moçambicanas: literatura e nacionalidade. Lisboa: Vega, 1994.

FANON, Frantz. Pele negra, máscaras brancas. Salvador: Fator, 1983.

FERNANDES, Gabriel. Em busca da Nação: Notas para uma reinterpretação do Cabo Verde crioulo. Florianópolis: UFSC, 2006.

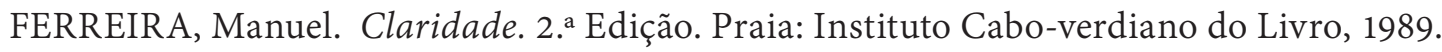

FERREIRA, Manuel. Literaturas Africanas de Expressão Portuguesa. São Paulo: Ática, 1987.

GARMES, Hélder. A convenção formadora: uma contribuição para a história do periodismo literário nas colônias portuguesas. São Paulo: USP, 1999.

GOMES, Simone Caputo. Cabo Verde: Literatura em chão de cultura. São Paulo: Ateliê Editorial, 2008.

GOMES, Simone Caputo. "Mulher com paisagem ao fundo", in: África e Brasil: Letras em Laços, org. Maria do Carmo Sepúlveda e Maria Teresa Salgado, São Paulo: Atlântica, 2000.

GOMES, Simone Caputo. Uma recuperação de raiz: Cabo Verde na obra de Daniel Filipe. Praia: Gráfica do Mindelo, 1993.

HAMILTON, Russell G. Literatura africana, literatura necessária, II: Moçambique, Cabo Verde, GuinéBissau, São Tomé e Príncipe. Lisboa: Edições 70, 1984.

LARANJEIRA, Pires. Literaturas Africanas de Expressão Portuguesa. Lisboa: Universidade Aberta, 1995. 
LOBO, Andréa. Sobre mulheres fortes e homens ausentes? Pensando conjugalidades como processos em Cabo Verde. Sociedade e Cultura, Goiânia, v. 19, n. 2, p. 13-25, jul./dez. 2016. Disponível em: $<$ https://www.revistas.ufg.br/fchf/article/view/48666/23961> Acesso em: 03 de Jan, 2020.

LOPES, Baltasar. Chiquinho. Mindelo: Editora Claridade, 1947.

LOPES, Manuel. Os flagelados do vento leste. Lisboa, Ulisseia Editora, 1959.

MADEIRA, João Paulo. A Construção da Nação em Cabo Verde: Do Nativismo ao Nacionalismo. Revista Desafios, Cátedra Amílcar Cabral. Cabo Verde, n. 2, p. 151-163, Nov, 2014. Disponível em: < https://www.unicv.edu.cv/images/stories/EdicoesUniCV/RevistaCT/revista_desafios2.pdf> Acesso em: 20 de Dez, 2019.

MONTEIRO, Félix. Eugénio Tavares: viagens, tormentas, cartas e postais. Praia/Mindelo: IPC, 1999.

OLIVEIRA, João Nobre De. A imprensa cabo-verdiana 1820-1975. Macau: Fundação Macau, 1998.

SALÚSTIO, Dina. Mornas eram as noites. Belo Horizonte: Nandyala, 2019.

SEMEDO, Manuel Brito: O modelo brasileiro e a literatura moderna cabo-verdiana: estudo comparado. São Paulo: USP, 2001.

SIQUEIRA, G. V. Q. A relação colonizador X colonizado em as Aventuras de Ngunga. Revista Arredia, Dourados, MS, Editora UFGD, v.3, n.5: 62-76 ago./dez. 2014. Disponível em: <http://ojs.ufgd.edu.br/ index.php/arredia/article/view/3241/2057> Acesso em: 03 de Jan, 2020.

SPIVAK, Gayatri Chakravorty. Pode o subalterno Falar? Belo Horizonte: Editora UFMG, 2010.

VASCONCELOS, João. Espíritos lusófonos numa ilha crioula: língua, poder e identidade em São Vicente de Cabo Verde. In: Clara Carvalho; João De Pina Cabral, (Coords.), A Persistência da História: Passado e contemporaneidade em África. Lisboa: Imprensa de Ciências Sociais, 2004.

ZOLIN, Lúcia Osana. Crítica feminista. In: BONNICI, Thomas; ZOLIN, Lúcia Osana (Org.). Teoria Literária: abordagens históricas e tendências contemporâneas. 3. ed. Maringá: EDUEM, 2009. 
